\title{
A PRELIMINARY SYSTEM TO PREDIGT SNOW INSTABILITY USING ACOUSTIC EMISSIONS
}

\author{
By R. A. Sommerfeld \\ (Rocky Mountain Forest and Range Experiment Station, 240 West Prospect Street, \\ Fort Collins, Colorado 80526 , U.S.A.)
}

\begin{abstract}
Results from the last four winters' studies on acoustic emissions from snow slopes have shown that periods of higher noise in the frequency band 5 to $125 \mathrm{~Hz}$ are associated with periods of instability, but that the phenomenon of acoustic emissions from unstable snow is very weak. Interference with the acoustic emissions from extraneous sources such as chairlifts, trucks, and airplanes causes ambiguities in the data which interfere with the straightforward prediction of instability.

Spectra of the noises were examined, with the idea that filters might improve the signal-tonoise ratio. It was found that the noise generated by unstable snow can occur over a fairly wide range of frequencies and that there is no band of frequencies which is unique to unstable snow. It was found that the noise from the chairlift had a very stable spectrum and that it had a band from $5^{\circ}$ to $65 \mathrm{~Hz}$ which was pronounced and in which the snow noise was fairly low. The r.m.s. voltage in the band 5 to $\mathrm{r} 25 \mathrm{~Hz}$ can therefore be reduced by subtracting a proportion of the r.m.s. output of a narrow-band $55 \mathrm{~Hz}$ filter. By adjusting the constant of proportionality, it was possible to eliminate interference from the chairlift almost entirely, and this will be used.

Spectral analyses have also shown that ambiguities are generated by variations in the $60 \mathrm{~Hz}$ power-line noise. It is possible to suppress this with the use of filters, but without complex digital data manipulation, it is not possible to eliminate it.

The fact that the snow noise does not transmit over large distances means that events of interest should not occur simultaneously on two, widely spaced geophones. The system will include a geophone in an unstressed region whose r.m.s. voltage will be subtracted from that of the geophone in the stressed region to eliminate signals which are common to both. It is hoped that this technique will eliminate ambiguities caused by extraneous sources such as trucks and airplanes.
\end{abstract}

\section{PREVENTION OF AVALANGHES IN THE GUNES VALLEY IN T'IEN-SHAN, GHINA}

\author{
By Wang Yanlong, Xie Zichu, and Zhang Zhizhong* \\ (Lanzhou Institute of Glaciology and Cryopedology, Academia Sinica, Lanchou (Lanzhou), \\ Peoples Republic of China)
}

Abstract. A section of the highway through the Gunes valley can be seriously interrupted by avalanching; in I 966-67 traffic was interrupted for four months. About 86 places are threatened by avalanches, most of which are channelled avalanches that do not reach the highway every year.

* Wade-Giles: Wang Yen-lung, Hsieh Tzu-ch'u, and Chang Chih-chung. 
A comprehensive programme to study the avalanches was begun in 1967 on the basis of which avalanche protective works were undertaken in 1974-75 and their effectiveness analysed in 1976-77. Most of these depend on local material; the main rock deposits available are andesite, which has good permeability and is very suitable for earthworks.

The most common type of defence used is the building of mounds, 4-6 m high, Io-1 $2 \mathrm{~m}$ wide, and $20-30 \mathrm{~m}$ long with a ditch dug in front. Such mounds have the effect of braking the avalanche flow and also of capturing snow on the uphill side. A second system is the terracing of slopes; beginning from the avalanche fracture line, earth is dug parallel to the contours. In two places dykes have been built to guide the snow, and in a few places avalanche sheds have been constructed, though because of expense these have been kept to a minimum. As the soil and climatic conditions are very suitable, tree planting around structures is a successful way of increasing avalanche protection.

During the analysis of effectiveness snow-fall as recorded was heavy, but the defences were effective and avalanches did not seriously interrupt the highway.

\title{
GEAR-TYPE GLIDE-METER AS AN INSTRUMENT FOR FORECASTING FULL-DEPTH AVALANGHES
}

\author{
By Yutaka Yamada \\ (Institute of Snow and Ice Studies, National Research Centre for Disaster Prevention, \\ Nagaoka, Niigata-ken, Japan 940)
}

Abstract. This paper is concerned with the variation of snow glide and its predictability in full-depth avalanches. From field measurements of snow glide using a newly developed gear-type glide-meter which is fixed to the ground and which measures the amount of glide as the angle of rotation of a gear, the following characteristics are deduced: (I) the variation of gliding rate is composed of both short-term and long-term variations, and (2) the existence of correlation between the short-term variation and the relative frequency of avalanches is recognized. 